\title{
Innovation in Health Informatics Conference in Spain: Conclusions on the Responsibility to Use Patient Data and Big Data Methods to Improve Healthcare
}

\author{
C. L. Parra-Calderón, G. Gómez-Soriano, J. Galván-Romo, L. Sáez-Ayerra \\ Spanish Society of Health Informatics, Madrid, Spain
}

\section{Background}

For 23 years, the Spanish Society of Health Informatics (SEIS) has organized a yearly conference including workshops, debate sessions, and lectures on a given health informatics topic with the objective of discussing, obtaining consensus, and producing a synthesis on the chosen topic. This conference gathers health informatics professionals from the industrial sector, public and private health providers, researchers, and innovators, all of them being related to the selected topic.

In Spain, since more than a decade, most of the public and private health care providers are using health information systems with a high degree of adoption, which has generated an enormous amount of digitized health data. The quality of such data can be very disparate being rarely represented using standards, but its volume is so high that the application of Big Data methods to search for patterns and regularities that could have an impact to improve health and healthcare is an opportunity that cannot be discarded.

Non-specialized media frequently address the issues related to patient data re-use with a lack of rigor, stimulating a controversy that puts the focus on ethical and defensive aspects and does not mention the possible benefits of using patient health data in the scientific and social fields. Besides, this information is frequently pointing out how suspicious any attempt to reuse health information could be, emphasizing the possible threats against personal data protection.
Big Data in Health is still not operating, but it continues to grow, surely, to conceal very useful knowledge about long-term effects of medicines, lifestyle, and health interventions [1]. SEIS considers that we should take advantage of the asset that Big Data in Health represents. Not doing so entails a great responsibility of the Spanish Health System that someday stakeholders can question.

Among the events that our society organizes every year, we decided to address this topic in the 2016 SEIS conference, usually dedicated to analyzing trends and challenges of a subject, with a systematized methodology, differentiated from other conventional scientific conferences organized by SEIS.

\section{General Objective of the Conference}

The XXIII Conference on Health Informatics in Andalusia, organized from 15 to 17 June 2016, aimed at providing a forum for the discussion and the analysis of the benefits that Big Data in Health can offers [2]. The objective was to make the actors understand that we had a responsibility to use, in an appropriate manner and with all the necessary safeguards, the existing patient data to generate knowledge, thus contributing to progress in health sciences and improving health care. As a result, a synthesis document has been written, including some proposals of the measures necessary to promote the effective advances of Big Data in Health.

\section{Methodology of the Conference}

We started working in the pre-conference phase, which lasted six months, from the beginning of 2016. Our Society has an Institutional Advisory Committee and an Advisory Committee of the Spanish Industry, which collaborate with the Conference Program Committee to prepare the conference. This phase identified the issues, the key speakers, the structure of the conference, the list of participants and the sessions to be included, and finally, the expected results.

Key issues related to Big Data in Health were analyzed and discussed in workshops and use case presentations: real usefulness of the available information, determinants of its use, real potential and limitations, current and future capabilities of the technology, main technological challenges, analysis of ethical issues, available and desirable normative regulation, impact of the new General Data Protection Regulation of the European Union, lessons learned from experiences in other sectors and success cases in the healthcare domain.

The conference had the following schedule, with an inaugural plenary session, workshops, discussion sessions, and a final synthesis:

1. Inaugural Plenary Session. This session had a didactic and formative focus and aimed at establishing a conceptual and terminological convergence among the participants to synchronize their points of view. First, a keynote lecture presented a report of SEIS about "Chal- 
lenges of health data analysis." Then, three keynotes speakers introduced some key issues: "Big data, concepts, and scope of available technologies", "Ethical and regulatory aspects of Big Data in Health: the responsibility to make it possible", and "Big data in Health for whom and for what?" Each keynote presentation was followed by an interactive debate with all attendees.

2. Workshops. They were organized in four rooms in parallel. Workshops were the occasion to analyze in depth and in a very participative way key issues related to the implementation of Big Data in Health. Each workshop identified some questions to address recommendations and conclusions during the synthesis.

- Ethical and normative context: European and Spanish regulations, disassociation of data, legitimate and prohibited uses of data, authorization of access, role of ethical committees, intellectual and industrial property rights, public-private partnerships, protection and transfer models, business models.

- Organizational Impact: change management, healthcare process management, and healthcare delivered model.

- Impact on Management and Planning: predictive models of healthcare resources and performance evaluation.

- Impact on Healthcare and Research Workshop: Big Data in clinical practice (predictive medicine, risk stratification, proactive medicine, integration of clinical data with genomic data, Big Data algorithms in health and research (clinical trials and public health).

3. Discussion Sessions. They were plenary sessions, sequentially organized after workshops, during the afternoon of the second day. During the Discussion Session, six success cases and experiences with a certain level of maturity were presented and discussed.

4. Synthesis. The synthesis included a participatory plenary session to discuss the provisional conclusions. Some recommendations related to the results of the workshops and cases were used to produce a Position Paper of our Society.

\section{Results of the Conference}

Details of what happened during the conference are described in the SEIS journal [3]. 242 professionals attended the Conference (from the health informatics sector, both vendors from technology companies and health care providers, mostly from the public health system). Invitations were sent according to regional health ministries, the companies, and the Ministry of Health (in Spain, competencies in Health are regional). There were four keynote speakers, eight workshop peer co-chairs, forty workshop participants, six case speakers and five scientific rapporteurs. Workshops presented as results a selection of the relevant shared questions to be addressed.

- The Ethical and Normative Context Workshop selected four questions: "Who owns the data that healthcare providers use?"; "What do we propose to ensure that anonymization is safe?"; "What kind of information/training should be implemented for the citizens to know the destination of their personal data?"; and "What would you consider to be the most relevant and urgent aspects to be regulated by the agents of European governments?"

- The Organizational Impact workshop selected five questions: "What do we look forward with the adoption of Big Data in Health? What problems could we solve?"; "How will Big Data affect healthcare processes? How will this affect organizations? What changes are needed?"; "Big Data in research: How to take advantage? What is the degree of truthfulness? How will it affect the scientific method?"; and "Could we define the best provision model for using Big Data services in Health?".

- The Impact on Management and Planning Workshop selected four questions: "How to improve active participation and patient safety?"; "How to generate "shared knowledge" (new scientific evidence)?"; "Which algorithms for diagnosis and treatment with Big data should be public and which should be private (copyright, patent)?"; and "How to generate adequate investment in IT infrastructure for Big Data and new digital vision of health services?".
- The Impact on Healthcare and Research Workshop selected three questions: "Support for decision-making so that Big Data helps improve decision-making in real-time"; "Collective behavior: Use Big Data techniques to improve the real-time management of population (epidemic, catastrophe, etc.)"; and "Precision Healthcare."

From the discussions on the questions identified in the workshops and the key issues following the case sessions, we synthesized and elicited a list of recommendations as statements, entitled "Big Data in Heath Statements by SEIS", about the relevant issues to be addressed by the Spanish Health System agents for the development of the application of Big Data in Health at a national level. This declaration is expected to be disseminated to identified stakeholders.

The statements by SEIS are the following:

1) Instruments with a lot of potentialities.

Big Data in Health represents a set of data-driven services able to produce new useful knowledge in order to identify how to better prevent, treat, and care diseases, and how to improve the management of health services.

2) Ethical responsibility. The solidarity principle, on which the Spanish Health System is based, forces to consider all the information generated in healthcare activities as a common and useful patrimony for the continuous improvement of the individual and collective health as well as to manage the resources in an efficient way. Consequently, this information must be used jointly employing the equity, lawfulness, loyalty, and clearness principles. Public entities have the ethical responsibility of facilitating the use of this common patrimony and to encourage the normalization and the appropriate use of the shared data among the different system agents and the supply of infrastructures that support the exchange of information within the Spanish Health System.

3) Privacy guaranteed. The development of Big Data in Health must be based on the rigorous respect of the law concerning data protection, taking into account the rights, limits, guarantees, and responsibilities that ensure the protection of 
people regarding the treatment and exploitation of their data.

4) Lofty cost-opportunity. The National and Regional Governments in the Spanish Health System have the responsibility to promote Big Data in Health as a driving of the biomedical knowledge, the translational research, and the generation of internal efficiency as well as high productivity of the industrial infrastructure. Delay in the development of Big Data causes a loss of health opportunities for the individuals, the population, the science, and the industry.

5) Current scenarios. The use of Big Data in Health would allow us to achieve, in a short period, some fundamental improvements such as, i) the reduction of the cycles about the knowledge of diseases, the suitability of diagnostic algorithms, and the efficacy of treatments, ii) the improvement of vigilance and intervention systems about the risks for Public Health that could achieve an accuracy without precedents, and iii) the increase of the efficacy in translational research processing biomedical and social data repositories, in multiple formats, including multiple perspectives and with continued feedback.

6) Strategic priority. Therefore, Big Data in Health should be a strategic priority for the Spanish Government to invest in the following years.

\section{Acknowledgments}

The authors wish to acknowledge the following participants of the conference: others SEIS Board members, keynote speakers, workshop co-chairs and participants, case speakers, scientific rapporteurs and sponsoring companies.

\section{References}

1. Parra-Calderón CL. Big data in health in Spain: now is the time for a national strategy. Gac Sanit [Internet]. SESPAS;2016;30(1):63-5. Available from: http://dx.doi.org/10.1016/j.gaceta.2015.10.005 PMID: 26613831

2. SEIS. XXIII Jornadas Nacionales de Informática Sanitaria en Andalucía [Internet]. 2016. Available from: http://www.seis.es/JornadasAndalucia16/

3. SEIS. Big Data Sanitario. La responsabilidad de aprovechar la información generada. I+S [Internet]. 2016;119(XXIII Jornadas Nacionales de Informática Sanitaria en Andalucía). Available from: http://www.seis.es/imagenes/REVISTAS/119.pdf 